\title{
A construção do problema na pesquisa sobre política educacional: contribuições para o debate
}

\author{
The construction of the problem in researches on educational policy: \\ contributions to the debate \\ La construcción del problema en la investigación sobre política educativa: \\ contribuciones al debate
}

\author{
ALCIVAM PAULO DE OLIVEIRA \\ http://orcid.org/0000-0002-5637-0890 \\ Universidade Federal de Pernambuco \\ Faculdade de Educação \\ Departamento de Fundamentos Sociofilosóficos da Educação \\ Pernambuco, PE, Brasil \\ ROSILDA ARRUDA FERREIRA \\ http://orcid.org/0000-0002-4244-991X \\ Universidade Federal do Recôncavo da Bahia \\ Faculdade de Biologia \\ Centro de Ciências Agrárias, Ambientais e Biológicas \\ Amargosa, BA, Brasil
}

\begin{abstract}
Resumo: A construção do problema de pesquisa é o foco deste artigo. Partindo dos debates sobre a fundamentação epistemológica da análise das políticas educacionais, identifica a necessidade de se propor caminhos que auxiliem na construção do problema da pesquisa. Da filosofia, adota sua postura diante da realidade, baseada na crítica ampla, histórica e sistemática. Das ciências políticas, traz a contribuição da "Policy Analysis" proposta por Frey (2000). Do campo da análise das políticas públicas em educação, recorre às contribuições da Rede de Estudos Teóricos e Epistemológicos em Política Educativa (RELEPE), por meio dos estudos de Mainardes e Tello (2015a; 2015b). Como resultados desse diálogo, apresenta uma proposta de construção do problema da pesquisa em políticas educacionais.
\end{abstract}

Palavras-chave: Epistemologia; Problema de Pesquisa; Políticas Educacionais.

\begin{abstract}
The focus of this paper is the construction of the research problem. Starting from the debates on the epistemological foundation of the analysis of educational policies, it identifies the need to reflect on the construction of the research problem. From philosophy, the paper adopts the posture towards reality based on broad, historical, and systematic criticism. From political sciences, it adopts the contribution of the "Policy Analysis" proposed by Frey (2000). From the field of public policy analysis in education, it draws on the contributions of the Network for Theoretical and Epistemological Studies in Educational Policy (RELEPE), through the studies of Mainardes and Tello (2015a; 2015b). As a result of this dialogue, the paper presents a methodological proposal of the construction of the research problem in educational policies.
\end{abstract}

Keywords: Epistemology; Research Problem; Educational Policies. 
Resumen: La construcción del problema de la investigación es el foco de este articulo. A partir de los debates sobre la base epistemológica del análisis de las politicas educativas, identifica la necesidad de proponer formas de ayudar en la construcción del problema de la investigación. Desde la filosofía, adopta su postura ante la realidad, basada en una crítica amplia, histórica y sistemática. De las ciencias políticas aporta la contribución del "Análisis de politicas" propuesto por Frey (2000). En el ámbito del análisis de políticas públicas en materia de educación, aprovecha las contribuciones de la Red de estudios teóricos y epistemológicos sobre políticas educativas (RELEPE), a través de los estudios de Mainardes y Tello (2015a; 2015b). Como resultado de este diálogo, se presenta una propuesta para construir el problema de investigación en politicas educativas.

Palabras-clave: Epistemología; Problema de Investigación Cientifica; Políticas Educativas.

\section{INTRODUÇÃO}

No contexto atual, a formação em pesquisa na área das ciências sociais é um desafio complexo. Por um lado, temos as dificuldades impostas pelo "clima" das discussões em torno da crise dos paradigmas e, até mesmo, da crise da própria concepção de paradigmas (LOSADAS y CASAS, 2008). Por outro lado, o sistema formativo de pesquisadores tende a ser passível de críticas (TELLO, 2011), enquanto a necessidade de certas habilidades e competências exigidas desses mesmos pesquisadores parecem ser difíceis de serem desenvolvidas.

Esse desafio foi colocado em relevância especificamente no campo da análise das Políticas Públicas em Educação pela Rede de Estudos Teóricos e Epistemológicos em Política Educativa (RELEPE), motivado pela preocupação com o lugar de um enfoque epistemológico na análise das políticas públicas (MAINARDES, 2009). Segundo seus representantes, haveria a tendência nesse campo de estudo de se seguir determinada metodologia sem a devida sustentação epistemológica, atentando contra a solidez e a coerência dos processos de pesquisa (TELLO, 2012).

Para enfrentar tal desafio, a RELEPE propõe que os pesquisadores precisam considerar três níveis para promoverem a fundamentação epistemológica e superarem os déficits constatados: i) a escolha da perspectiva epistemológica; ii) a escolha do posicionamento epistemológico; iii) e, por fim, a escolha dos métodos de coleta e análise de dados, o que é chamado de epistemedotologia. Segundo os autores, a explicitação dessas escolhas possibilitaria a construção da pesquisa epistemologicamente fundamentada e informaria a cosmovisão do pesquisador, viabilizando a sustentação de suas conclusões a partir de um quadro epistemológico definido. 
Mas, por onde começar? Quer dizer, num contexto de fragilidade formativa, há de se considerar a dificuldade de pesquisadores iniciantes para chegar a esse nível de consistência epistemológica na formulação de um problema de pesquisa, apesar dos manuais sobre técnica de pesquisa científica insistirem na primordialidade da sua construção, como nos indicam os trabalhos de Bravo (2001), Vasconcelos (2002), Rudio (2007), Fachin (2005), Lakatos (2003), Minayo (2012), Gil (2008), Trivinos (1987), entre outros.

A relevância do problema de pesquisa pode ser visualizada na Figura 01 que apresenta o esquema pelo qual, em geral, podemos visualizar a construção de um projeto de pesquisa e o lugar do problema a ser investigado.

Figura 01 - Esquema geral do projeto de pesquisa

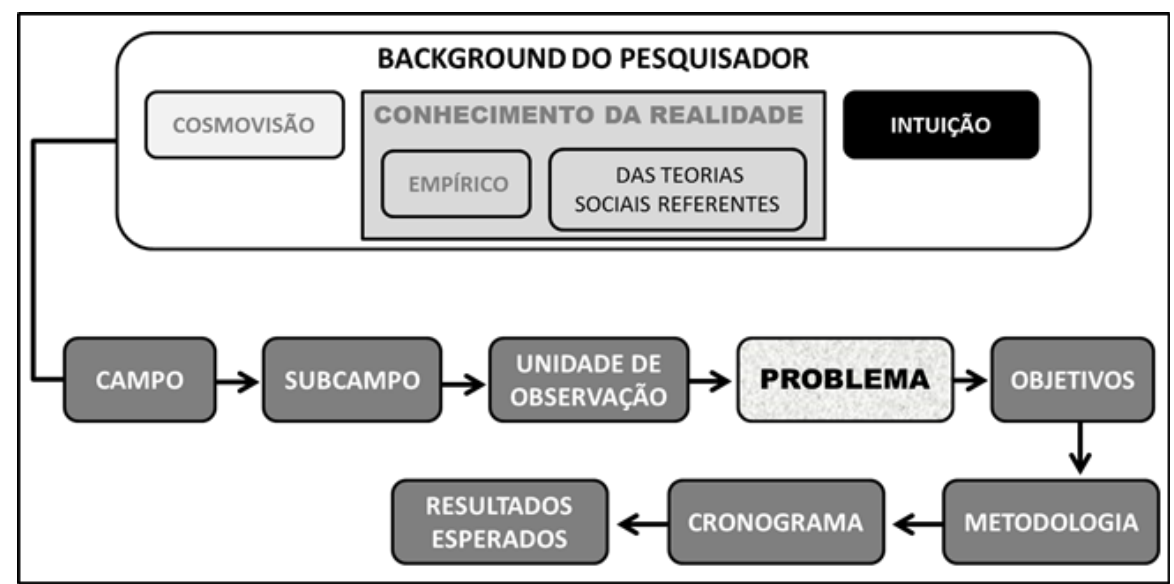

Fonte: Elaboração própria

$\mathrm{Na}$ figura 01, destacamos, por um lado, o background do pesquisador como a fonte de todo o trabalho e vamos explorá-lo melhor adiante. Por outro, ao se tratar dos campos do conhecimento, identifica-se que o sistema de pesquisa no Brasil, estabelecido pela CAPES e CNPq, é organizado em quatro níveis: grande área; área, subárea e especialidades. Num paralelo, política educacional é uma especialidade da subárea planejamento e avaliação educacional, pertencente à área educação que, por sua vez, se agrega à grande área ciências humanas. Optamos aqui pela simplificação e aproximação com o esquema proposto na figura 01, nomeando a educação como campo e a política educacional como subcampo, o qual se vincula diretamente à unidade de observação, compreendida como realidades que se pretendem observar (BRAVO, 2001). 
O procedimento sugerido no fluxograma da Figura 01, contudo, não é receita a ser seguida e, sendo um processo teórico, requer não apenas racionalidade, mas também intuição. De toda sorte, do esquema proposto na figura 01 podemos inferir a centralidade do problema no processo de pesquisa. Antecipando-se ou não, é ele que guiará e especificará a pesquisa: podemos ter diversas pesquisas tendo como objeto um determinado campo (por exemplo, Educação), que possui diversos subcampos (por exemplo, Política Pública de Educação) com diversas unidades de observação (por exemplo, Programa Universidade para todos ProUni) sobre as quais se pode fazer uma infinidade de pesquisas, entretanto só haverá uma que pode ser identificada como original para cada problema. Havendo mais de uma para o mesmo problema, ela será replicação.

Ao tomar o problema como o centro do projeto de pesquisa, a sua formulação parece ser também o momento mais difícil. Corroborando essa postura, os "corredores" dos programas de pós-graduação ressoam a esfíngica pergunta que os orientandos de mestrado e doutorado escutam: mas, qual é seu problema de pesquisa mesmo?

Por sua vez, os manuais, ao mesmo tempo em que denotam a importância do problema, apontando suas características, tendem a não detalhar os procedimentos para sua formulação. Trata-se de um processo para o qual parece não haver caminhos que se possa sugerir, ou o aprendizado se dá pelo "[...] treinamento [que] desempenha papel fundamental nesse processo" (GIL, 2008, p. 26), sendo um processo que se deve à “... visión y agudeza intuitiva del investigador, en la que no existen reglas fijas y sirven de poco las fórmulas previas" (BRAVO, 2001, p. 57).

Mas, seria possível sugerir procedimentos que possam ajudar os pesquisadores iniciantes na construção do problema de pesquisa? Neste artigo buscamos contribuir para a resposta a esta pergunta, considerando a experiência dos autores e o diálogo entre ciência e filosofia.

\section{O PROBLEMA}

Para melhor visualizarmos o processo de construção do problema, simplifiquemos o esquema da Figura 01, apresentando a Figura 02: 
Figura 02 - Esquema do projeto simplificado

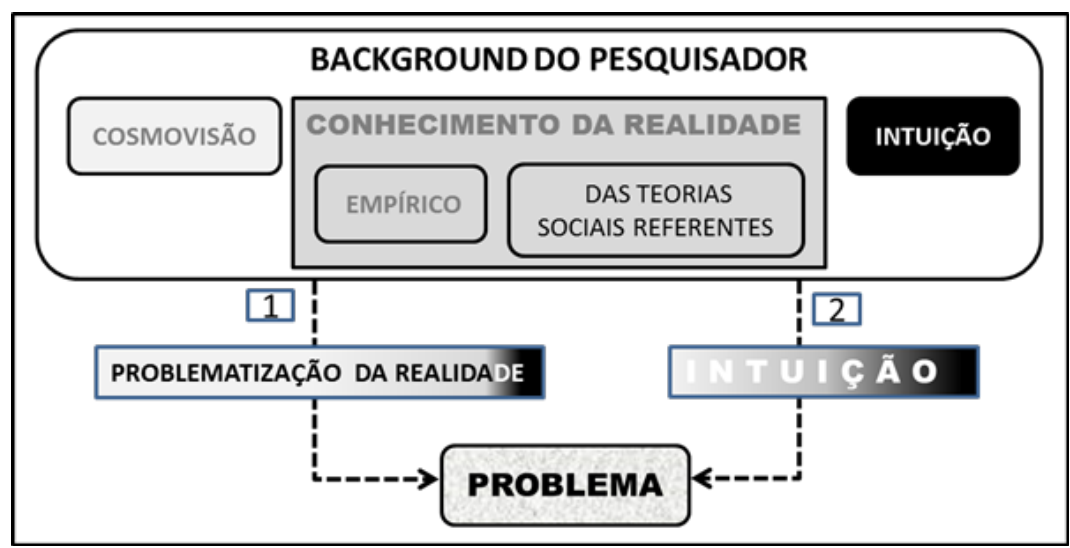

Fonte: Elaboração própria.

Segundo a simplificação proposta, o problema advém por um processo sistemático de problematização da realidade ou por uma intuição. Em ambos os casos, afirma-se que se trata de uma proposição, como pergunta ou hipótese, definidora do que será pesquisado e de como será feita a pesquisa. Mesmo no caso de advir por intuição, o problema exigirá um processo de legitimação, submetendo-o aos procedimentos da problematização para que possa ser situado na cartografia das pesquisas. Assim sendo, o principal caráter do problema não está em ser pergunta ou hipótese, mas em ser resultante de um processo de problematização da realidade. Para melhor compreender esse processo, se faz necessário que aprofundemos o sentido do termo "problema".

Gil (2008) diferencia problemas de engenharia (referentes ao "como fazer") e de juízos de valores (o que é melhor, o que é mal) dos problemas da ciência que seriam definidos pela suscetibilidade ao método científico: possibilidade de observar, testar e "manipular" variáveis envolvidas.

Vasconcelos (2002), por sua vez, fala de problema como senso comum, indicando que o diferencial deste para o problema científico é sua amplitude e ineditismo, mesmo que não tenha sido reconhecido "pela sociedade ou constituído ainda uma 'disfuncionalidade' aberta”" (VASCONCELOS, 2002, p. 142)

Para Saviani (1996), todavia, não existem problemas técnicos, morais ou científicos, mas posturas técnicas, morais, religiosas ou científicas no enfrentamento dos problemas. Por isso, antes de qualificar uma proposição como problema científico, é importante perguntar se realmente trata-se de um problema porque, segundo o autor, houve uma vulgarização do sentido desse termo, isto é, definese como problema o que se pode chamar de "questões" (como em matemática), 
"enigmas" (como perguntas sem respostas), "dificuldades" (materiais, pessoais, coletivas), "desafios" (tarefas que exigem soluções) e etc., quando, na verdade, o sentido do termo deve ser buscado na sua radicalidade, por meio da reflexão filosófica, como busca de sentido para a realidade ou de resposta que as pessoas procuram num dado momento da vida:

\begin{abstract}
Com efeito, todos e cada um de nós nos descobrimos existindo no mundo (existência que é agir, sentir, pensar). Tal existência transcorre normalmente, espontaneamente, até que algo interrompe o seu curso, interfere no processo alterando a sua sequência natural. Ai, então, o homem é levado, e obrigado mesmo, a se deter e examinar, procurar descobrir o que é esse algo. E é a partir desse momento que ele começa a filosofar. O ponto de partida da filosofia é, pois, esse algo a que damos o nome de problema. Eis, pois, o objeto da filosofia, aquilo de que trata a filosofia, aquilo que leva o homem a filosofar: são os problemas que o homem enfrenta no transcurso de sua existência (SAVIANI, 1996, p. 10)
\end{abstract}

É importante perceber que o autor se refere à filosofia como postura humana diante da realidade que tem na perplexidade, diríamos nós, seu momento de manifestação, e não como ordem de conhecimento erudito. A dificuldade de encararmos o problema dessa forma estaria no esquecimento do dramatismo que ele carrega: problemática é uma situação que impossibilita a continuidade da existência se não houver uma solução, de tal forma que problema tem o sentido de crise, manifesta tanto na inadequação das soluções existentes, quanto na ausência de uma solução adequada para o problema. Aqui encontramos a essência do problema: a necessidade! Não basta ser uma pergunta, ela precisa ser necessária, ser condição de continuidade para quem a faz. "Algo que eu não sei não é problema; mas quando eu ignoro alguma coisa que eu preciso saber, eis-me, então, diante de um problema”. (SAVIANI, 1996, p. 14, grifo nosso)

Há o risco de que essa dramaticidade existencial tenda a nos remeter a uma dimensão subjetivista (subjetivamente distorcida) do problema, quem sabe, reduzindo-o a questões existenciais? Sim, mas Saviani vai demonstrar que a problemática é, como de resto, a própria existência humana, algo que possui uma dimensão subjetiva e outra objetiva, dialeticamente relacionadas:

A verdadeira compreensão do conceito de problema supõe, como já foi dito, a necessidade. Esta só pode existir se ascender ao plano consciente, ou seja, se for sentida pelo homem como tal (aspecto subjetivo); há, porém, circunstâncias concretas que objetivizam a necessidade sentida, tornando possível, de um lado, avaliar o seu caráter real ou suposto (fictício) e, de outro, prover os meios de satisfazê-la. Diríamos, pois, que o conceito de problema implica tanto a conscientização de uma situação de necessidade (aspecto subjetivo) como uma situação conscientizadora da necessidade (aspecto objetivo). (SAVIANI, 1996, p. 14)

248 - Rev. Bras. Polít. Adm. Educ. - v. 37, n. 1, p. 243 - 265, jan./abr. 2021 
Observe-se que a "construção" do problema (em seu sentido pleno) implica na reflexão ao exigir que o sentimento de necessidade, em seu caráter existencial para o indivíduo e para a sociedade, seja trazido à consciência, assumindo-se subjetivamente as condições objetivas que geram o problema.

Dessa forma, o "Problema" da pesquisa precisa ser, antes de tudo, um problema no seu sentido mais profundo, materializando a crise diante da necessidade e, por isso, exigindo respostas; essa necessidade é identificada nas condições objetivas da realidade, pois é a realidade que exige respostas; e essa necessidade deve ser assumida subjetivamente pelo pesquisador. É por isso que na problematização excluímos "problemas" que parecem satisfazer apenas as curiosidades do pesquisador ou, de maneira reversa, são enfrentados como tarefas alienadas e alienantes pelo pesquisador para satisfazer outras necessidades pessoais, antes mesmo dele cumprir aqueles requisitos científicos ou operacionais (BRAVO, 2001).

Uma vez satisfeitas tais condições podemos então falar do caráter epistêmico do Problema, como proposição que direciona, qualifica e legitima a postura científica que irá enfrentá-lo.

\section{O BACKGROUND QUE POSSIBILITA A PROBLEMATIZAÇÃO}

O caminho que leva à problematização da realidade, como passo primeiro ou segundo no caso de vir antes a intuição, é resultante de um conjunto de fatores que o pesquisador traz consigo, como indica a Figura 03. 


\section{Figura 03 - O background do pesquisador}

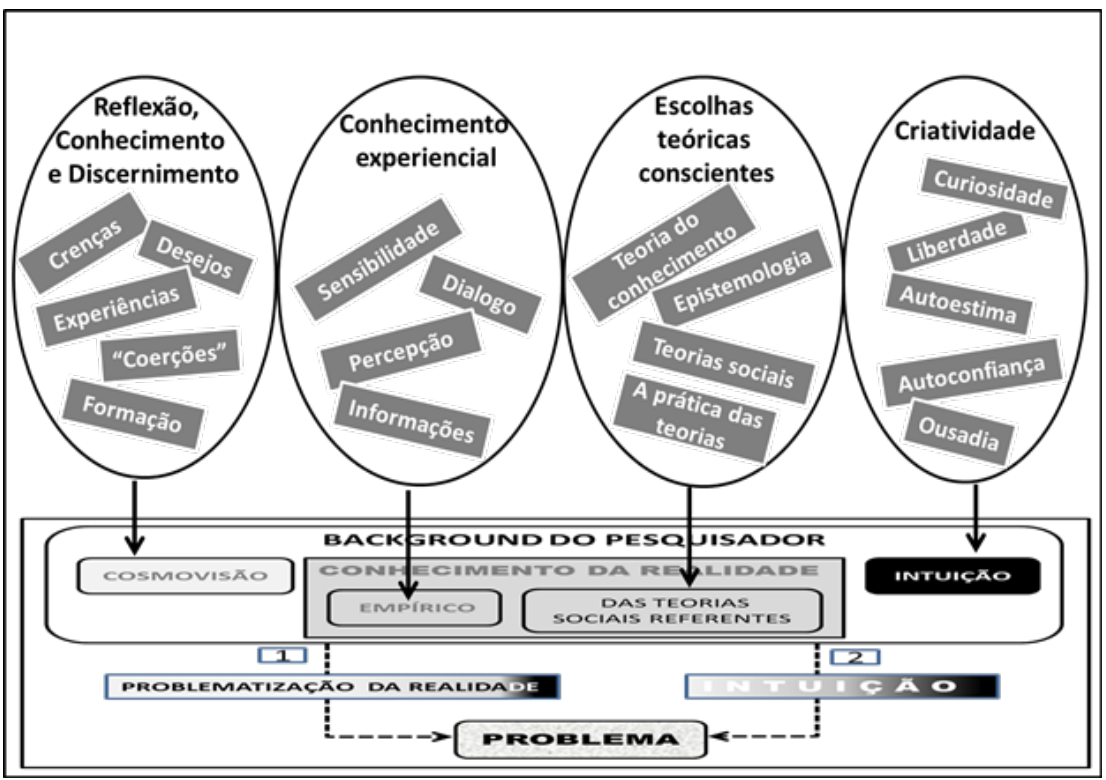

Fonte: elaboração própria

Perceba-se que, dos fatores elencados, à exceção do círculo referente às escolhas teóricas, todos os pesquisadores os trazem consigo, variando o peso que cada um deles possui em suas escolhas e decisões. As condições imediatas são dadas por um background constituído pela cosmovisão (TELLO, 2012), ou seja, pelas crenças, desejos, coerções, mais ou menos conscientes do pesquisador como pessoa existente. O ideal é que o pesquisador tenha o máximo de consciência de sua cosmovisão, exercitando em seu cotidiano a reflexão sobre suas ações (porque fiz, escolhi, recusei e etc.). Faz parte desse processo o grau de uso de sua intuição, ou seja, a curiosidade, a liberdade, a coragem, a autoestima e a autoconfiança que direcionam sua ousadia para ser intuitivo. Mas também são componentes que vão depender de condições objetivas, principalmente daquelas estabelecidas na relação com seu orientador ou com a comunidade de pesquisadores da qual faz parte. Com efeito, esses ambientes, como todo ambiente institucionalizado, implicam sempre em tensão entre a liberdade, a autoestima, a criatividade e a ousadia, de um lado; e de outro, as regras, a modéstia, a realização de protocolos pré-estabelecidos e o comedimento.

Posteriormente devemos considerar que para escolher um campo e um subcampo de pesquisa, deve-se ter o mínimo de conhecimento sobre ele, conhecimento que é ainda mais exigido quando se trata de formular o problema. O conhecimento teórico é certamente o mínimo pressuposto, mas é necessário 
atentar, também, para o conhecimento como resultante da experiência (BONDIA, 2002). Não é simplesmente se informar e saber emitir opiniões, mas construir sabedorias sobre esse recorte, sabedoria que deve ser resultante do saborear o saber acessado. É no conviver com o campo e o subcampo que, havendo curiosidade e sensibilidade no pesquisador, se perceberá problemas, identificando-se os sujeitos e suas ações, compreendendo-se nexos causais entre procedimentos, enfim, indose além de descrição pura e simples da realidade. A vivência dentro da escola, por exemplo, nos dá uma percepção muito diversa entre o que a literatura fala sobre a elaboração do Projeto Político Pedagógico (subcampo da gestão escolar) e o que acontece efetivamente nas reuniões, decisões e elaborações do texto.

Nesse cenário, assenta-se um conjunto de escolhas que precisam ser objeto de atenção do pesquisador. No que se refere ao círculo das escolhas teóricas, este exige formação e domínio sobre teorias diversas que se colocam antes do domínio das teorias sociais e após elas. A teoria do conhecimento precisa considerar decisões acerca das relações entre sujeito e objeto e a possibilidade do conhecimento em geral, o critério de verdade e a lógica de regulação do real, por exemplo, decisões que estão subjacentes as teorias sociais. O mesmo se pode dizer da epistemologia em seu caráter de fundamentação científica das ciências humanas, implicando em escolhas sobre o caráter das regulações gerais da sociedade ou simplesmente sobre sua impossibilidade; sobre a unidade fundamental do arranjo social ser o modo de produção, a ação racional do sujeito ou o fato social, para ficarmos nas escolhas entre os clássicos da sociologia.

Dentre esses aspectos da reflexão e tomada de decisão, as escolhas com relação às teorias sociais parecem ser mais acessíveis talvez por serem a ponta do iceberg sociológico e, mesmo assim, deve-se considerar a diversidade de tradições e os riscos do ecletismo (TELLO e MAINARDES, 2015b) para que não se tente a fusão artificial do conflito com o consenso (GOMES, 1983) ou se acredite que uma só teoria consiga explicar ou compreender toda a realidade (WEBER, 2004).

\section{PROBLEMATIZAÇÃO DA REALIDADE}

Perceba-se que a problematização pressupõe as escolhas sobre o campo, o subcampo e a unidade de observação, sendo esta última o recorte da realidade do qual o problema emerge como intuição ou como problematização da realidade.

Quando dizemos que o problema emerge como intuição, estamos nos referindo ao “(...) momento em que temos uma compreensão total, direta e imediata de alguma coisa, ou o momento em que percebemos, num só lance, um caminho para a solução de um problema científico, filosófico ou vital" (CHAUÍ, 2001, p. 77), que acontece antes mesmo da problematização. 
De qualquer forma, a construção do problema de forma intuitiva, como afirmamos anteriormente, exige a análise de sua legitimidade e pertinência, isto é, um processo de verificação pela problematização da realidade. $\mathrm{O}$ mesmo processo que será feito caso a intuição não venha.

A problematização da realidade recortada (unidade de observação) é fruto de um processo de análise crítico, sistemático e radical, articulando-se teoria e prática, num processo de ação-reflexão-ação que faz emergir os "problemas" na medida em que, como observador, o sujeito assuma uma postura, assim como indicado na Figura 04 em continuidade com a Figura 03.

\section{Figura 04 - Problematização da realidade}

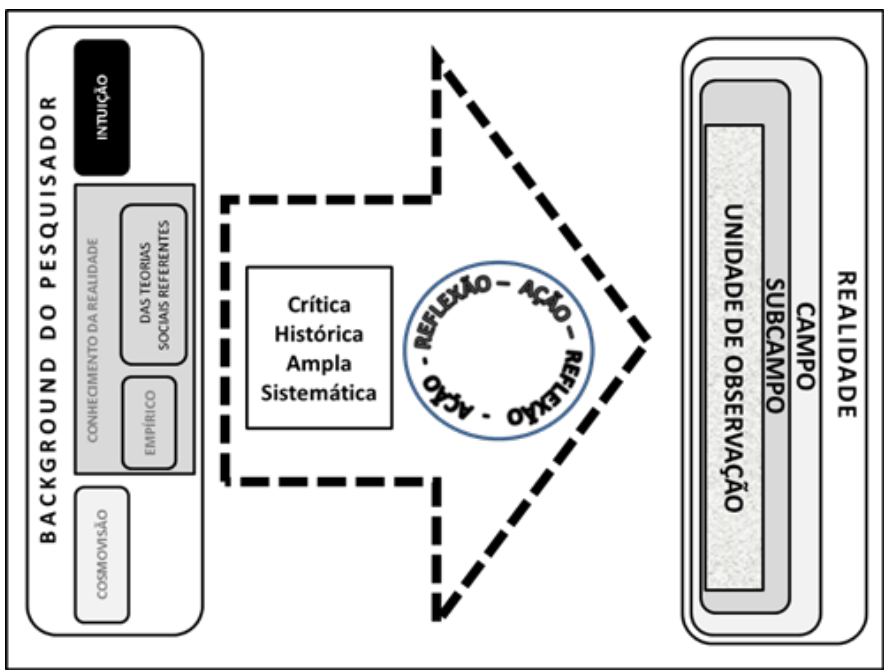

Fonte: Elaboração própria.

A ação-reflexão-ação exige, ainda, a superação do paradigma que o senso comum nos impõe sobre a relação entre teoria e prática. O fato é que, via-deregra, nossa educação nos leva a compreendermos essa relação como sendo linear, ou seja, o senso comum tende a estabelecer a relação entre ação-reflexãoação, exigindo uma sequência temporal entre os dois momentos.

Outra forma de dizer isto é: uma solução traz consigo sempre novos problemas, de modo que a relação entre planejar - executar - avaliar - planejar segue um esquema circular e não linear. Nenhuma ação começa do zero, com um diagnóstico, porque a própria decisão de fazer um diagnóstico provém de uma ação anterior que demonstrou ser arriscado começar a agir sem um diagnóstico 
prévio, portanto, são as ações que provocam as mudanças de diagnóstico, que por sua vez, provocam mudanças no planejamento - na forma de planejar, inclusive; que provoca as mudanças no processo de avaliação e assim em diante.

Pensando-agindo dessa forma teremos mais facilidade em identificar a mútua dependência entre teoria e prática: só podemos construir modelos (teorias) representativos da realidade, porque interagimos (ação) com essa realidade; e toda interação com a realidade possibilita a (re)construção de modelos. Obviamente há muitos modelos pelos quais optamos em não os realizar por razões diversas (por não terem sentido, por não nos dar satisfação ou por serem mentirosos), como há interações que realizamos desconcentradamente, sem reflexão (por não precisarem de concentração ou por serem chatos e etc.). Isso, todavia não exclui o vínculo essencial entre teoria e prática.

Os componentes da cosmovisão, do conhecimento da realidade e da intuição possibilitam, assim, a postura crítico-reflexiva diante da realidade, problematizando-a e não apenas contemplando-a ou descrevendo-a. Desse processo resulta a formulação do problema de pesquisa, caso o façamos metodologicamente.

\section{A METODOLOGIA DA PROBLEMATIZAÇÃO VISANDO À FORMULAÇÃO DO PROBLEMA DE PESQUISA}

Aqui temos o foco de nosso tema: Como é possível pôr em ação a cosmovisão, o conhecimento e a intuição, por meio da postura crítica na açãoreflexão-ação para formular um problema? Ou, como problematizar a realidade?

Ainda pensando em termos de sugestão, ao definir o campo, o subcampo e a unidade de observação como processo de delimitação do problema, o pesquisador precisará realizar procedimentos ao modo de uma pesquisa exploratória, visando aprimorar ideias e intuições (GIL, 2008). Esse processo exigirá uma investigação prévia sobre sua unidade de observação, o que poderá ser realizado a partir de três passos: delimitar a unidade de observação, identificar as variáveis e verificar possíveis relações entre elas, como indica a Figura 05, em continuidade com a Figura 04. 
Figura 05 - Problematização para a pesquisa

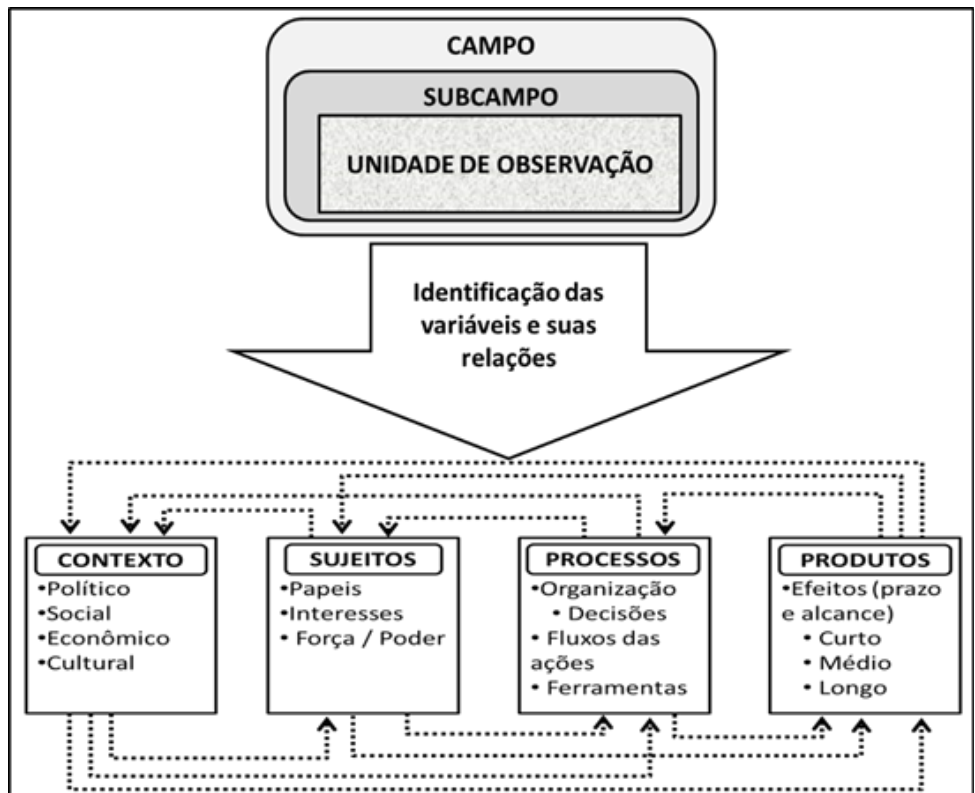

Fonte: elaboração própria.

1) Delimitar a unidade de observação

Bravo (2001) define unidades de observação como entidades substantivas que possuem características específicas e são mais ou menos autônomas em relação ao conjunto da realidade, mas que não são independentes do todo. Não obstante, podemos agrupar determinados elementos que se relacionam e delimitar uma unidade. Essa unidade pode ser, por exemplo:

a) uma instituição (a escola). Apesar de sabermos que toda instituição é resultante de uma prática social e histórica (interdependência com o todo), ela tem características (sujeitos, processos, produtos e contextos) que a tornam específicas em relação a outras instituições ou organizações na sociedade;

b) uma ação, por exemplo, as políticas públicas. Mais uma vez sabemos que as políticas públicas, como ação do Estado (AZEVEDO, 1997), estão intimamente vinculadas ao todo da sociedade, todavia, podemos identificar nelas processos específicos que diferem, por exemplo, da produção de bens materiais e, por conseguinte, identificar os sujeitos envolvidos, os processos que realizam seus mecanismos de planejamento, execução e avaliação, os produtos que ela gera e o contexto em que acontece; 
c) uma categoria profissional. Sabemos que cada profissão tem relação com as outras porque há uma divisão social do trabalho (funcional ou conflitiva), porém, isso não nos impede de reconhecer as fronteiras dadas pelas suas finalidades (produtos gerados), pelas competências exigidas (sujeitos), pelos mecanismos próprios de sua produção (processos), e pelo contexto em que ela se insere (como definir a categoria de programadores fora do contexto das modernas tecnologias da informação?).

Poderíamos falar ainda de unidades que se caracterizam como fenômenos sociais (que envolvem múltiplos sujeitos, processos, produtos e contextos) como é o caso da discriminação racial no Brasil ou grupos culturais, ou de subjetividades... A lista é longa. Importa apreender essa lógica de que, sendo a realidade complexa e sistêmica, sua análise científica se faz a partir, necessariamente, do recorte em unidades de observação (BRAVO, 2001).

2) Identificar as variáveis dessa unidade

As variáveis são os elementos que compõem a unidade de observação: professor na escola, moldura legal na política ou mecanismos de produção na categoria profissional. Essas variáveis precisam ser elementos: i) observáveis empiricamente; ii) passíveis de descrição; iii) suscetíveis a mudanças; iv) reveladores de mudanças relacionadas a outras variáveis.

Essas variáveis serão identificadas como os sujeitos participantes, descritos em seus atributos de identidade, papeis, interesses, força (poder); como processos que a fazem funcionar, a exemplo da organização de papeis e fluxos de ações ou ferramentas que possibilitam seu funcionamento e método de decisão; como produtos que devem ser gerados identificados materialmente ou na forma de efeitos descritos em seu poder de alcance social e temporal; e, seu contexto, compreendido como equivalente às dimensões política, social, econômica e cultural.

A grande "mágica" do pesquisador será identificar as relações que acontecem entre as variáveis. Dizemos grande mágica porque aqui se revelará a originalidade da pesquisa, quando se pode perceber novas relações ou ficar nas costumeiramente identificadas, a exemplo da relação entre micro e macro realidade em conformidade com referências que passam a ser incorporadas nos estudos como repetição pura e simples, ou, quando não, de forma dogmática recorrendo a fórmulas tradicionais (BRANDÃO, 2001). 
Eis, portanto, a sistematização do caminho que estamos propondo até aqui: após a problematização da realidade, tendo escolhido a unidade de observação, o pesquisador irá descrevê-la e analisá-la (suas variáveis e as possíveis relações entre elas). Esse processo contribuirá para a identificação de erros, acertos e obscuridades que permitirão a formulação de perguntas ou hipóteses.

\section{A FORMULAÇÃO DO PROBLEMA: PERGUNTA OU HIPÓTESE?}

A Figura 06, em continuidade com a Figura 05, apresenta o esquema dos procedimentos para formulação do problema:

Figura 06 - Formulação do problema

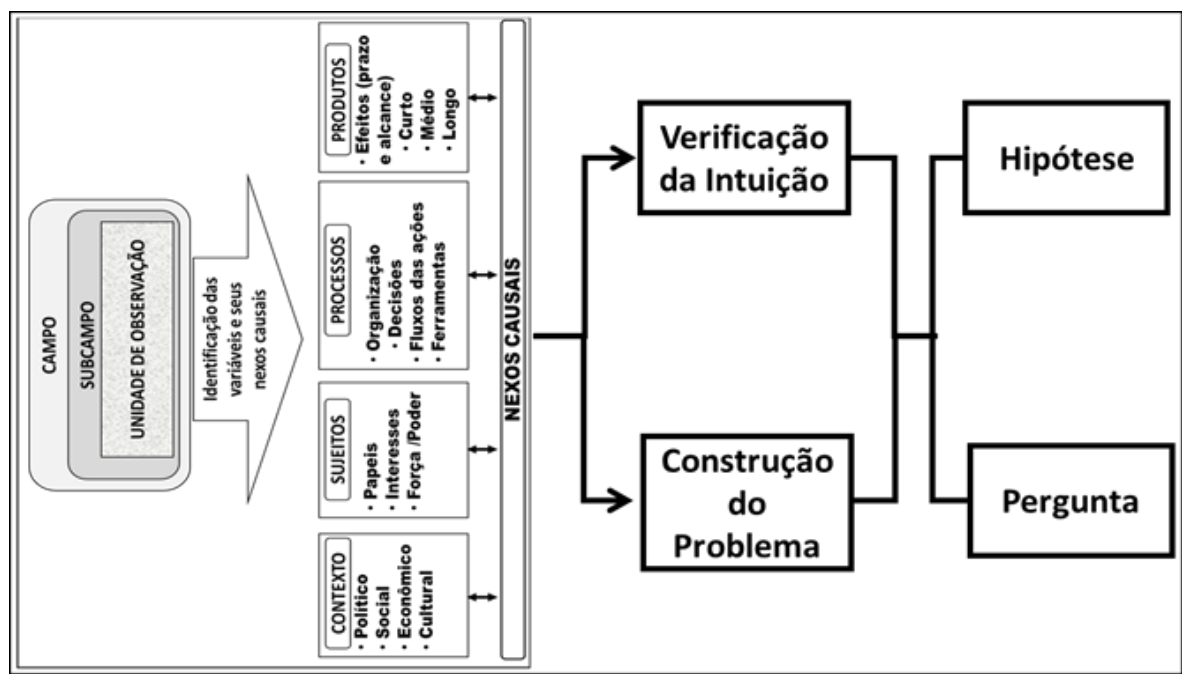

Fonte: elaboração própria.

Em geral, a literatura sobre metodologia científica trata a hipótese como sinônimo de pergunta, ou considera a hipótese em seu sentido amplo, como antecipação de resposta a uma pergunta a exemplo do texto abaixo:

No capítulo anterior, foi dito que a pesquisa científica se inicia sempre com a colocação de um problema solucionável. O passo seguinte consiste em oferecer uma solução possível, mediante uma proposição, ou seja, uma expressão verbal suscetível de ser declarada verdadeira ou falsa. A essa proposição dá-se o nome de hipótese. Assim, a hipótese é a proposição testável que pode vir a ser a solução do problema. (GIL, 2008, p. 31) 
Nesses casos fica a indagação, qual realmente é a função da hipótese? Ou, por que eu devo antecipar uma resposta para o problema construído? São raríssimas as perguntas de qualquer natureza nas quais seu propositor não tenha uma hipótese de resposta. Contudo, se ele a apresenta, a resposta que poderá obter será, necessariamente, um "sim" ou um "não" independente da modalidade dessa hipótese (GIL, 2008). Ademais, dificilmente o percurso da pesquisa não irá influenciar a observação e a análise, tendendo sempre a direcioná-las para a resposta (de "sim" ou "não") da hipótese colocada, ou seja, haverá pouco espaço para novas descobertas.

Essas indagações são refletidas por Tello (2011) ao questionar a possibilidade de sinonímia entre problema e hipótese. Para o autor, trata-se na verdade de duas lógicas distintas de pesquisa, a hipótese segue a lógica da verificação: "[...] al modelo de verificación, es decir, esto se da cuando con una teoría se va a verificar la realidade" (TELLO, 2011, p. 231), devendo a pesquisa responder com um sim ou um não à única questão apresentada: essa unidade de observação confirma ou nega a hipótese proposta.

Por sua vez, a pergunta segue a lógica do descobrimento, "[...] a diferencia de la bipótesis, no se tienen dos posibles respuestas (de afirmación o negación de la hipótesis). El investigador desconoce a priori las múltiples relaciones, conflictos, estados de situación, etc. que arrojará su investigación". (TELLO, 2011, p. 232)

Na perspectiva da pergunta, a problematização será justamente a postura do pesquisador em questionar: o que é? Como é? Por que é assim? E para quê é? Feita a análise, as perguntas exigirão respostas mais profundas e consistentes, quanto mais amplo e consistente for aquele background do pesquisador. Com efeito, responder que o ProUni é uma política do Governo Federal brasileiro não satisfará a alguém que saiba a diferença entre política de governo e política de Estado; dizer que ele foi construído porque Lula, presidente à época de sua criação, queria acabar com a discriminação racial, não satisfará a alguém que considere a complexidade da relação entre Estado e sociedade na produção de políticas públicas; responder que ele funciona de forma democrática, não satisfará alguém que saiba do poder que tem o Ministério da Educação na definição de mecanismos para seu funcionamento ou da influência que a Controladoria Geral da União e o Tribunal de Contas da União exercem sobre sua execução; enfim, afirmar que serve para oferecer cursos de segunda categoria para os negros, implicará em questionamentos por parte de quem conhece o desempenho dos bolsistas no Exame Nacional de Desempenho de Estudantes - ENADE.

Por sua vez, quando se formula não uma pergunta, mas uma hipótese, segundo Tello (2011), deve se tratar de hipótese científica, sociológica e não da suposição de respostas a uma pergunta (por melhor que ela seja formulada). 
Destarte, a problematização cujo resultado é uma hipótese pressupõe um trabalho muito mais amplo do pesquisador, ele deve ter um background que inclua não apenas a análise da unidade de observação, mas também o domínio da teoria social proponente da hipótese.

Dessa forma, uma coisa é a problematização do ProUni que busca encontrar nas suas motivações, nos sujeitos implicados, no seu modo de funcionar, nos seus resultados e contextos os problemas como resultante de desconhecimentos, erros e acertos com seus respectivos efeitos colaterais; outra, é a que propõe a pergunta se ele corresponde a um vetor de ampliação do capital cultural e social dos negros. Nesse último caso, está pressuposto que a teoria do capital social de Bourdieu (2007) ou de Putnam (2006) é um modelo (teoria) que explica a realidade da dominação social, cabendo ao pesquisador analisar a submissão ou não da unidade de observação chamada ProUni, a esta ou aquela teoria.

Assim, problematizada a realidade e eleita a opção por uma pergunta ou por uma hipótese, seguem-se alguns elementos para os quais precisamos estar atentos:

1) clareza gramatical - a formulação precisa ser gramaticalmente clara, de forma a que não deixe dúvidas sobre o que se quer saber (pergunta) ou o que se está afirmando;

2) precisão epistemológica - a pergunta ou hipótese deve ter o máximo de precisão epistemológica devendo-se, se necessário, definir as categorias que as compõem. É importante lembrar que em termos das ciências sociais algumas categorias tendem a possuir diversas conceituações em função das teorias sociais que as constroem. No exemplo acima referido, capital social é uma categoria definida de formas diferentes, ainda que muito próximas, por Bourdieu (2007) e Putnam (2006);

3) empiricidade analítica (MINAYO, 1994) - a pergunta ou a hipótese será o pressuposto para a definição dos objetivos, imbricando o processo de coleta e análise de dados. Considere-se que isso exigirá dados que sejam acessíveis. O melhor é que essa acessibilidade respeite os recursos disponíveis (materiais e humanos) e o tempo adequado ao prazo estipulado pelo projeto de pesquisa;

4) articulação com uma teoria social - a formulação da pergunta e ainda mais da hipótese exige não apenas uma fundamentação epistemológica que possa ser dada a partir apenas da cosmovisão do pesquisador, mas também de uma apurada reflexão fundamentada na perspectiva epistemológica que implique no posicionamento epistemológico fazendo emergir daí o enfoque 
epistemetodológico (TELLO E MAINARDES, 2015a) referente ao campo e à unidade de observação. Quer dizer, mesmo que o pesquisador tenha um background que facilita essa articulação, é muito importante que na problematização ele refaça essa análise para ter certeza de suas escolhas.

\section{A PROBLEMATIZAÇÃO NO SUBCAMPO DA POLÍTICA EDUCACIONAL}

As análises de políticas públicas da educação focam, em geral, em programas de ação, isto é, políticas públicas no sentido estrito do conceito, traduzindo o Estado em ação (AZEVEDO, 1997). Para tanto, há uma série de posicionamentos epistemológicos ou teorias específicas para sua análise, a exemplo do institucionalismo, neo-institucionalismos, ecletismo, dentre outros (TELLO, 2012). A escolha por uma dessas teorias no trabalho de pesquisa deve ser da forma mais consciente possível, porque ela, a teoria escolhida, é o eixo e "[...] la nervadura de la categoría epistemologías de la política educativa, dado que es aquí donde se pone en juego la presencia de la cosmovisión del investigador" (TELLO, 2012, p. 57) e de seu próprio posicionamento político diante da realidade.

Considerando, todavia, que nesse momento inicial, tendo consolidada a escolha da unidade de observação, o mais importante é realizar o exercício de problematização da realidade ao modo de investigação exploratória (GIL, 2008). Sim, é verdade, como dissemos anteriormente, que se trata de um exercício em que se põe em ação a cosmovisão do pesquisador, em outras palavras, não é neutro, como nada em pesquisa o é. Não obstante, a escolha consciente por uma das teorias gerais da Sociologia e por sua correspondente teoria específica poderá se consolidar ao longo da realização da pesquisa na medida em que o problema construído vá também se consolidando. Nesse momento se faz necessário o uso de um mínimo de teorias na forma de modelos analíticos, que ajudem na problematização.

Com o intuito de avançar nas contribuições que esse artigo se propõe a trazer, apresentamos alguns procedimentos, ancorados em Frey (2000), que estão expostos como modo de estudo exploratório da pesquisa em que se procura identificar a unidade de observação e as variáveis da análise. Vale registrar que essa é uma contribuição possível, dentre muitas outras que poderão ser delineadas em função do uso de outras referências teóricas. 
A Figura 07 apresenta um quadro sinótico dos procedimentos sugeridos, pressupondo que a unidade de observação é uma determinada Política Pública "Alfa".

Figura 07 - Analisando a unidade de observação

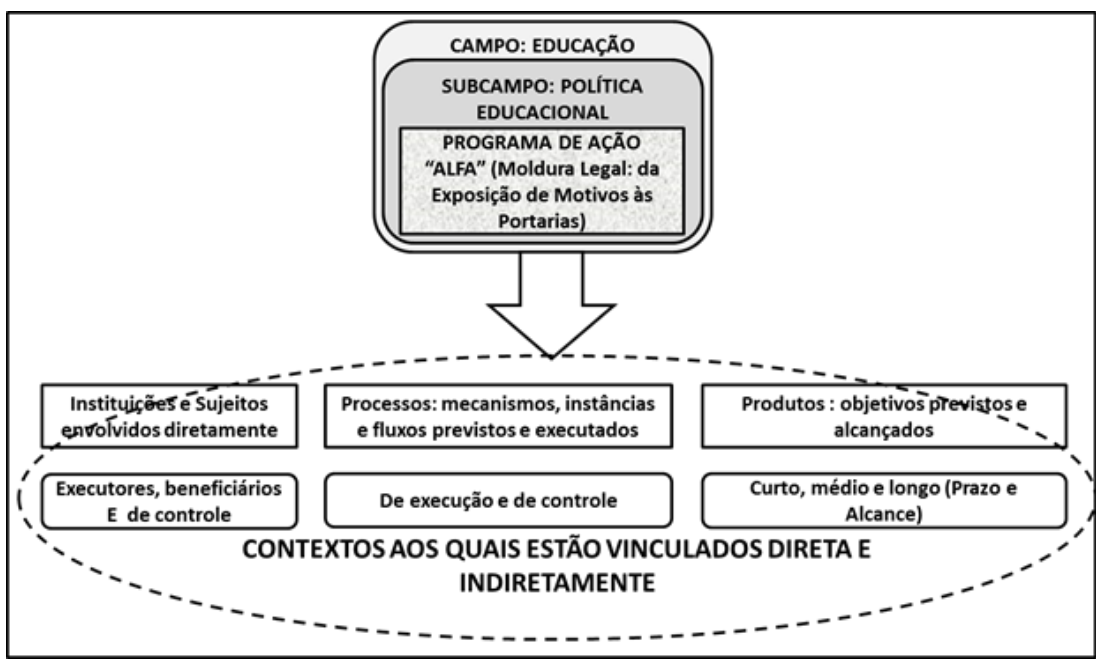

Fonte: elaboração própria

A unidade de observação a ser analisada será a moldura legal do Programa formulado por meio de lei ou decreto, incluindo a exposição de motivos que em geral acompanha mensagens de envio de leis ao Congresso Nacional pelo Poder Executivo ou Judiciário, ou na argumentação quando de origem da sociedade ou dos próprios congressistas em que se pode encontrar as variáreis relativas à motivação para a proposição. Inclui ainda as portarias e normas subsequentes à lei que normatiza os procedimentos executivos e um plano de ação (item mais importante de todos).

As variáveis principais que se poderiam identificar a partir da referência teórica tomada como exemplo são:

a) as instituições compreendidas em seu sentido lato, portanto, envolvendo órgãos estatais, de classe profissional, empresas, organizações não governamentais, igrejas, enfim, tudo que possa ser compreendido como organização que traduza interesses coletivos e os canalizem (FREY, 2000). A análise deve localizar as variáveis: instituições e sujeitos envolvidos ou a arena política (FREY, 2000) que inclui pelo menos três categorias de sujeitos e instituições: executores, beneficiários e aqueles que exercem o papel de controle ou de avaliação da ação, no Brasil, os Tribunais de Contas e a Controladoria Geral da União; 
b) os processos de planejamento, execução, controle e avaliação das ações, materializados nas estruturas organizativas, nos mecanismos de discussão e decisões e nos equipamentos envolvidos. A identificação desse conjunto permite desenhar o diagrama de fluxo (NAVARRO et al, 2006) em que se podem definir os marcos e o itinerário das ações, identificando os efeitos e as relações possíveis entre as ações previstas e como elas se encadeiam para provocar os resultados previstos.

c) os produtos são identificados nos objetivos e metas previstos e nos resultados alcançados, considerando que se trata de uma ação que já teve pelo menos um ciclo completo realizado. Não raro a moldura legal e mesmo o plano de ação apresenta princípios, diretrizes, objetivos, mas esquecem das metas, dificultando a avaliação dos resultados. Isso poderá exigir um trabalho maior da pesquisa que terá ela mesma de construir essa relação entre objetivos e resultados físicos. Nesse sentido, é importante considerar três tipos de resultados: os esperados e alcançados, os esperados e não alcançados e os alcançados inesperadamente. Seja por erros no diagnóstico, no planejamento ou na execução da política, suas consequências nunca serão de todo controladas. Os resultados devem ser considerados em sua gradação temporal (curto, médio e longo prazo) e espacial (curto, médio e longo alcance). Esses resultados são encontrados em relatórios dos próprios executores, como por exemplo, no caso do Ministério da Educação, relatórios produzidos pelo Instituo Nacional de Estudos e Pesquisa Educacionais Anísio Teixeira - INEP, mas é determinante que se busque também em outros tipos de fontes que possam trazer informações relevantes sobre o foco da política em análise;

d) os contextos precisam ser especificados. Potencialmente, todas as políticas estão vinculadas a todos os contextos, mas é preciso identificar aqueles contextos vinculados mais fortemente à política seja por ser seu lócus original, seja por seu lócus beneficiário imediato.

Identificadas e descritas as variáveis, o pesquisador precisa estabelecer as relações ente elas. O exercício analítico, ancorado em referências teóricas, precisa procurar relações em diversas perspectivas: informais, como aquelas que acontecem sem serem direta e imediatamente desejadas; as que não são explicitadas nos documentos; e as que expressam contradições e mútuas determinações.

Nessa identificação das relações, talvez seja importante considerar o ciclo da política, isto é, ir além dos documentos oficiais e tentar identificar o processo pelo qual uma necessidade social transformou-se em demanda política, entrando na agenda de deliberações e ações. Dizemos talvez, porque aí podem se localizar as principais incógnitas ou explicações para os resultados alcançados ou não. 
Diante do resultado construído, torna-se relevante fazer perguntas como: "quem"? "Por que"? "Para que"? e "Como"?, a partir das quais podem emergir erros e/ou obscuridades, em outras palavras, problemas como perguntas ou hipóteses cujas respostas ou verificação são condição para a plena existência da política pública, ou para a manutenção de sua integridade (sentido objetivo do problema) e que, simultaneamente, sejam de interesse para o próprio pesquisador (sentido subjetivo da pesquisa), aspectos que dialogam todo o tempo ao longo do desenvolvimento da pesquisa social.

\section{CONSIDERAÇÕES FINAIS}

A nossa intenção foi mostrar como a construção do problema é o primeiro exercício do pesquisador que terá uma dupla função: exercício pedagógico e construção da fundamentação epistemológica.

Será exercício pedagógico porque implicará num aprendizado do campo de pesquisa e da unidade de observação; de aprendizado do seu "modo" de fazer a pesquisa, fazendo com que possa emergir uma espécie de consciência epistemológica e, finalmente, de aprendizado sobre si mesmo, sobre como é e como funciona sua cosmovisão, na medida em que apura sua consciência sobre si mesmo, sobre suas escolhas e suas concepções.

Será a construção de sua base epistemológica porque, na medida em que analisa e problematiza sua unidade de observação, irá tomando consciência de que as categorias utilizadas na análise não caíram do céu nem brotaram da terra, mas das opções que ele faz nas matrizes das teorias do conhecimento, das teorias sociais gerais e das teorias sociais específicas disponíveis. Processo que pode colaborar para se evitar o risco do ecletismo - aplicando conceitos irreconciliáveis - e do fundamentalismo epistemológico - forçando teorias a explicarem tudo que existe na realidade.

Enfim, espera-se que as discussões e sugestões do presente artigo contribuam para a fundamentação epistemológica da análise das políticas educacionais, ao trazer indicações sobre a construção de caminhos que auxilie na construção do problema da pesquisa nesse subcampo de conhecimento ancorados nas argumentações da filosofia e das ciências políticas. Esse é um desafio que precisa ser enfrentado para que se possa, por um lado, superar a tendência nesse campo de estudo, como nos diria Tello (2012), de se seguir determinadas teorias e metodologias sem a devida sustentação epistemológica e, por outro, desenvolver pesquisas que qualifiquem a produção do conhecimento sobre políticas educacionais. 


\section{REFERÊNCIAS}

AZEVEDO, J. M. L. A educação como política pública. Campinas: Autores Associados, 1997. (Coleção Polêmicas do Nosso Tempo)

BONDIA, J.L. Notas sobre a experiência e o saber da experiência. Rev Bras Educ., 19(1):20-9. Jan/fev/mar/abr. nº 19. 2002.

BOURDIEU, P. O capital Social: notas introdutórias. Os três estados do capital cultural, in Nogueira, Alice e Catani, Afrânio. Escritos de Educação. 9ed. Rio de Janeiro: Vozes, 2007.

BRANDÃO, Z. Para além das ortodoxias: a dialética micro/macro na sociologia da educação. Disponível em: <http://www.anped.org.br/outr7. doc>. Acesso em: 02 set. 2001

BRAVO, S. Restituto: técnicas de investigación: teoria y ejercicios. Madrid: Editorial Paraninfo: 2001.

CHAUÍ, M. Convite à filosofia. 12.ed. São Paulo: Ática, 2001

FACHIN, O. Fundamentos de Metodologia. 5 ed. São Paulo: Saraiva, 2005

FREY, K. Políticas públicas: um debate conceitual e reflexões referentes à prática da análise de políticas públicas no Brasil. Planejamento e políticas públicas, Rio de Janeiro, Instituto de Pesquisa Econômica Aplicada (IPEA), n. 21, p. 211 259, ISSN 0103-138, jun 2000.

GIL, A.C. Como elaborar projetos de pesquisa - 6. ed. - São Paulo: Atlas, 2008.

GOMES, C.A.C. Enfoques teóricos em sociologia da educação. II - O paradigma do conflito. Fórum Educacional, v. 7, nº 3, p. 85-104, jul./set. 1983.

LAKATOS, Eva M. Fundamentos da Metodologia Científica. $5^{\mathrm{a}}$ ed. São Paulo - Atlas: 2003

LOSADA, R. L y CASAS, A. C. Enfoques para el analisis politico - $1^{a}$ ed. Bogota: Editorial Pontificia Universidad Javeriana, 2008. 394 p. 
MAINARDES, J. Análise de políticas educacionais: breves considerações teórico-metodológicas. Itajaí: Revista Contrapontos: v.9, n 1, p. 4-16, jan/abr. 2009. Disponível em: file:///C:/Users/Micro/Downloads/971-2043-1-PB.pdf . Acesso em: 30 maio 2019.

MINAYO, M. C. (Org.) Pesquisa social: teoria, método e criatividade. Petrópolis, RJ: Vozes, 1994.

MINAYO, Maria Cecília de Souza. Análise qualitativa: teoria, passos e fidedignidade. Ciênc. saúde coletiva, Rio de Janeiro , v. 17, n. 3, p. 621-626, mar. 2012. Disponível em <http://www.scielo.br/scielo.php?script=sci_ arttext\&pid=S1413-81232012000300007\&lng=pt\&nrm=iso $>$. Acesso em 31 maio 2019. http://dx.doi.org/10.1590/S1413-81232012000300007.

NAVARRO et al, Hugo. Pauta metodológica de evaluación de impacto exante y ex-post de programas sociales de lucha contra la pobreza. Aplicación metodológica. Santiago de Chile: CEPAL, enero de 2006.

PUTNAM, Robert D. Comunidade e democracia: a experiência da Itália moderna. 5 ed. Rio de Janeiro: Editora FGV, 2006. 260 p. Tradução: Luiz Alberto Monjardim.

RUDIO, F. V. Introdução ao projeto de pesquisa científica. 34.ed. Petrópolis: Vozes, 2007. 131p Atlas, 2002

SAVIANI, D. Do Senso Comum à consciência filosófica. 12 ed. Campinas, SP: Autores Associados. 1996. 247 p.

TELLO, C. G. El objeto de estudio en ciencias sociales: entre la pregunta y la hipótesis. Cinta Moebio, 42, p. 225-242, 2011. Disponível em: <www.moebio. uchile.cl/42/tello.html> Acesso em: 26 jun. 2018

TELLO, C. G. Las epistemologías de la política educativa: vigilancia y posicionamiento epistemológico del investigador en política educativa. Práxis Educativa, Ponta Grossa, v. 7, n. 1, p. 53-68, jan./jun. 2012

TELLO, C.; MAINARDES Revisitando o enfoque das epistemologias da política educacional. Práxis Educativa, Ponta Grossa, v. 10, n. 1, p. 153-178, jan./jun. 2015a. 
TELLO, C.; MAINARDES, J. Pluralismos e investigación en política educativa una perspectiva Epistemológica In: Revista Mexicana de Investigación Educativa, vol. 20, núm. 66, julio-septiembre, Distrito Federal, México: Consejo Mexicano de Investigación Educativa, A.C. 2015b, pp. 763-788

TRIVINOS, A. N. S. Introdução à pesquisa em ciências sociais: a pesquisa qualitativa em educação. São Paulo: Atlas, 1987.

VASCONCELOS, Eduardo M. Complexidade e pesquisa interdisciplinar: epistemologia e metodologia operativa. Petrópolis, RJ: Vozes, 2002.

WEBER, M. Weber, Max. A ética protestante e o "espírito” do capitalismo. Tradução: Antônio Flávio Pierucci (Ed.). São Paulo: Companhia das Letras, 2004

\section{Alcivam Paulo de Oliveira}

Professor do Departamento de Fundamentos Sociofilosóficos da Educação do Centro de Educação da Universidade Federal de Pernambuco. Doutor em Educação (UFPE). E-mail: alcivampaulodeoliveira@gmail.com

\section{Rosilda Arruda Ferreira}

Professora do Curso de Licenciatura em Biologia, do Centro de Ciências Agrárias, Ambientais e Biológicas da Universidade Federal do Recôncavo da Bahia, atuando na área de sociologia e antropologia da educação. Doutora em Educação (UFSCar). E-mail: rosildaarruda@gmail.com 